\title{
Confinement dependence of electro-catalysts for hydrogen evolution from water splitting
}

\author{
Mikaela Lindgren ${ }^{*}$ and Itai Panas
}

\author{
Full Research Paper \\ Address: \\ Department of Chemical and Biological Engineering, Chalmers \\ University of Technology, S-412 96 Gothenburg, Sweden

\section{Email:} \\ Mikaela Lindgren * mikaela.lindgren@chalmers.se \\ * Corresponding author \\ Keywords: \\ confinement; corrosion; DFT; electro-catalysis; hydrogen evolution
}

Open Access

Beilstein J. Nanotechnol. 2014, 5, 195-201.

doi:10.3762/bjnano.5.21

Received: 05 September 2013

Accepted: 21 January 2014

Published: 24 February 2014

This article is part of the Thematic Series "Electrocatalysis on the $\mathrm{nm}$ scale".

Guest Editor: R. J. Behm

(c) 2014 Lindgren and Panas; licensee Beilstein-Institut.

License and terms: see end of document.

\begin{abstract}
Density functional theory is utilized to articulate a particular generic deconstruction of the electrode/electro-catalyst assembly for the cathode process during water splitting. A computational model was designed to determine how alloying elements control the fraction of $\mathrm{H}_{2}$ released during zirconium oxidation by water relative to the amount of hydrogen picked up by the corroding alloy. This model is utilized to determine the efficiencies of transition metals decorated with hydroxide interfaces in facilitating the electro-catalytic hydrogen evolution reaction. A computational strategy is developed to select an electro-catalyst for hydrogen evolution (HE), where the choice of a transition metal catalyst is guided by the confining environment. The latter may be recast into a nominal pressure experienced by the evolving $\mathrm{H}_{2}$ molecule. We arrived at a novel perspective on the uniqueness of oxide supported atomic Pt as a HE catalyst under ambient conditions.
\end{abstract}

\section{Introduction}

Molecular hydrogen produced by water splitting constitutes the archetypical energy carrier in chemistry and is a main target process for the future harvesting of solar energy. Today, water splitting represents large economical values, i.e., it comprises a significant fraction of the total industrial electric energy consumption in the USA [1]. Decisive factors jointly determining the efficiency of the electrochemical process are the reactions at the oxidizing anode as well as at the hydrogen evolving cathode. In two inspiring experimental studies [2,3], Subbaraman et al. reported enhanced hydrogen evolution activity in water splitting by tailoring $\mathrm{TM}(\mathrm{OH})_{2}-\mathrm{Pt}$ electro-catalyst/electrode assemblies, where TM represents $\mathrm{Mn}^{2+}, \mathrm{Fe}^{2+}$, $\mathrm{Co}^{2+}$ and $\mathrm{Ni}^{2+}$. The role of these hydroxides was to catalyze water dissociation. In this context, the objective of the present study is to contribute a novel descriptor for the electro-catalytic hydrogen evolution reaction (HER). It offers a complementary 
perspective on a recent study addressing the oxidation of zirconium alloys by water $[4,5]$. The overall reaction

$$
1 / 2 \mathrm{Zr}+\mathrm{H}_{2} \mathrm{O} \rightarrow 1 / 2 \mathrm{ZrO}_{2}+\mathrm{H}_{2}
$$

is taken to occur by water utilizing hydrolysis to penetrate the oxide scale along hydroxylated grain boundaries, see Figure 1a,

$$
\begin{aligned}
& {\left[\mathrm{Zr}^{\mathrm{IV}}-\mathrm{O}-\mathrm{Zr}^{\mathrm{IV}}\right]_{\text {grain boundary }}+\mathrm{H}_{2} \mathrm{O}} \\
& \rightarrow\left[\mathrm{Zr}^{\mathrm{IV}}-\mathrm{O}-\mathrm{H} \quad \mathrm{HO}-\mathrm{Zr}^{\mathrm{IV}}\right]_{\text {hydroxylated grain boundary }}
\end{aligned}
$$

These hydroxide ions subsequently react with transition metal decorated sites (see Figure 1a) and zirconium metal to produce $\mathrm{ZrO}_{2}$ in conjunction with transient transition metal associated hydride-proton (hydroxide) pairs (see Figure 1b) to restore the $\mathrm{ZrO}_{2}$ grain boundary according to

$$
\begin{aligned}
& {\left[\mathrm{Zr}^{\mathrm{IV}}-\mathrm{O}-\mathrm{H} \quad \mathrm{HO}-\mathrm{Zr}^{\mathrm{IV}}\right]+\left[\mathrm{Zr}^{\mathrm{IV}}-\mathrm{O}-\mathrm{M}^{\mathrm{X}}\right]+1 / 2 \mathrm{Zr}} \\
& \rightarrow\left[\mathrm{Zr}^{\mathrm{IV}}-\mathrm{O}-\mathrm{Zr}^{\mathrm{IV}}\right]+\left[\mathrm{HO}-\mathrm{Zr}^{\mathrm{IV}}-\mathrm{H}-\mathrm{M}^{\mathrm{X}}\right]+1 / 2 \mathrm{ZrO}_{2} \text {. }
\end{aligned}
$$

This can be subdivided into an anode process

$$
\begin{aligned}
& 1 / 2 \mathrm{Zr}+\left[\begin{array}{ll}
\mathrm{Zr}^{\mathrm{IV}}-\mathrm{O}-\mathrm{H} & \mathrm{HO}-\mathrm{Zr}^{\mathrm{IV}}
\end{array}\right] \\
& \rightarrow 1 / 2 \mathrm{ZrO}_{2}+\left[\mathrm{Zr}^{\mathrm{IV}}-\mathrm{O}-\mathrm{Zr}^{\mathrm{IV}}\right]+2 \mathrm{H}^{+}+2 \mathrm{e}^{-}
\end{aligned}
$$

where the $\left[\mathrm{Zr}^{\mathrm{IV}}-\mathrm{O}-\mathrm{Zr}^{\mathrm{IV}}\right]$ oxide grain boundary is recovered, and a cathode process

$$
\begin{aligned}
& {\left[\mathrm{Zr}^{\mathrm{IV}}-\mathrm{O}-\mathrm{M}^{\mathrm{X}}\right]+2 \mathrm{H}^{+}+2 \mathrm{e}^{-}} \\
& \rightarrow\left[\mathrm{Zr}^{\mathrm{IV}}-\mathrm{O}-\mathrm{M}^{\mathrm{X}-2}\right]+2 \mathrm{H}^{+} \\
& \rightarrow\left[\mathrm{HO}-\mathrm{Zr}^{\mathrm{IV}}-\mathrm{H}-\mathrm{M}^{\mathrm{X}}\right]
\end{aligned}
$$

is employed to decide the oxidation state $\mathrm{X}$. The subsequent chemical drive for $\mathrm{H}_{2}$ release into the confining grain boundary determines $\mathrm{M}$ and recovers the $\left[\mathrm{Zr}^{\mathrm{IV}}-\mathrm{O}-\mathrm{M}^{\mathrm{X}}\right]$ site (cf. Figure 1c)

$$
\begin{aligned}
& {\left[\mathrm{HO}-\mathrm{Zr}^{\mathrm{IV}}-\mathrm{H}-\mathrm{M}^{\mathrm{X}}\right]} \\
& \rightarrow\left[\mathrm{Zr}^{\mathrm{IV}}-\mathrm{O}-\mathrm{M}^{\mathrm{X}}\right]+\left[\mathrm{H}_{2}\right]_{\text {grain boundary }}
\end{aligned}
$$

Indeed, Equation 6 was found to be decisive for the fraction of hydrogen atoms not forming $\mathrm{H}_{2}$ but being absorbed in the $\mathrm{Zr}$ alloy according to

$$
\begin{aligned}
& {\left[\mathrm{HO}-\mathrm{Zr}^{\mathrm{IV}}-\mathrm{H}-\mathrm{M}^{\mathrm{X}}\right]+\mathrm{aZr}} \\
& \rightarrow\left[\mathrm{Zr}^{\mathrm{IV}}-\mathrm{O}-\mathrm{M}^{\mathrm{X}}\right]+\mathrm{Zr}_{\mathrm{a}} \mathrm{H}_{2}(\mathrm{~s}) .
\end{aligned}
$$

For completeness, a $1.1 \mathrm{eV} / \mathrm{H}_{2}$ drive to release $\mathrm{H}_{2}$ from the confining grain boundary was computed according to

$$
\left[\mathrm{H}_{2}\right]_{\text {grain boundary }} \rightarrow \mathrm{H}_{2}(\mathrm{~g})+[]_{\text {grain boundary }} .
$$

Utilization of the hydride-proton recombination channel (see Figure $1 b$ ), the correlation between the computed reaction energies for the HER, Equation 6, and the experimental hydrogen pick-up fractions (HPUF), i.e., the fraction of the hydrogen, which does not undergo hydrogen evolution but are instead picked-up by the alloy during zirconium oxidation by water, leads to a model as displayed in Figure 1e. It is noteworthy, that the energetics for the chemical reaction step in Equation 6 offers a measure of the confinement-dependent cathodic overpotential for the HER along the reaction channel (Equations 2-6). The relevance of the reversible hydride-proton recombination reaction (Equation 6) has recently been proposed in case of a nickel electro-catalyst supported by seven-membered cyclic diphosphine ligands containing one pendant amine, with the $\mathrm{Ni}$ supporting the hydride and the amine providing the proton in the hydride-proton recombination reaction [6].

\section{Results and Discussion}

In the following we introduce and employ the notion of "confinement effect" as a steric Pauli repulsion type interaction between $\mathrm{H}_{2}$ and a hydroxylated interface (see Figure 1c) upon hydride-proton recombination. First, we employ this notion in the context of hydride-proton recombination reactions to demonstrate how it decides which oxidation state $\mathrm{X}$ of metal ion M minimizes the overpotential for the HER, as quantified by the reaction Equation 6 (cf. Figure 1d,e). Second, it is shown how the emerging understanding is naturally extended to include electro-catalysts for HER under ambient conditions.

\section{Impact of confinement on HER during zirco- nium oxidation by water}

To investigate the confinement effect on the HER, we consider the zirconium oxidation by water (see Figure 1d). The difference between the two horizontal lines at $2.9 \mathrm{eV}$ and at $-0.2 \mathrm{eV}$ corresponds to the $3.1 \mathrm{eV} / \mathrm{H}_{2}$ [9] thermodynamic drive for HER in case of $\mathrm{Zr}$ oxidation by water under ambient conditions 
(a)

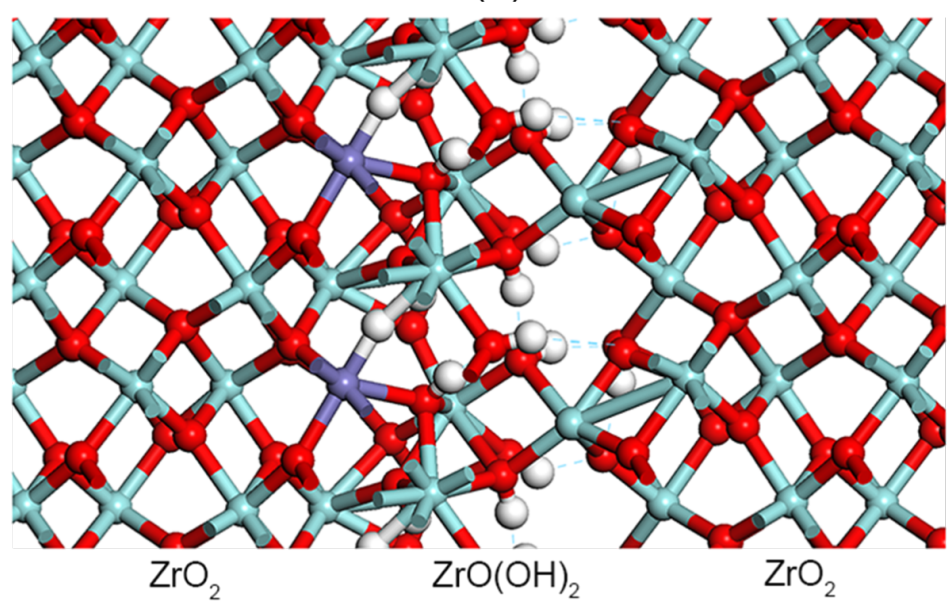

(b)

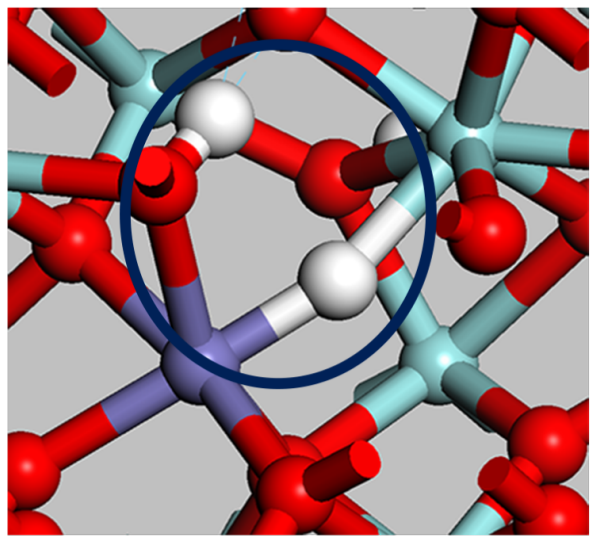

(d)

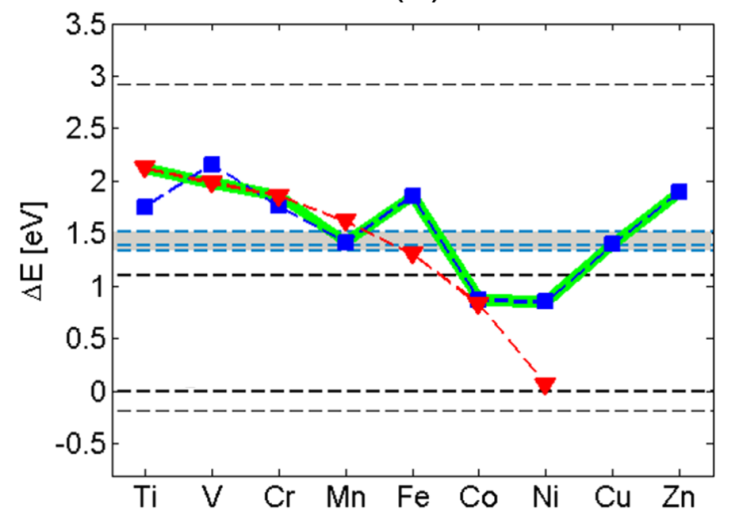

(c)

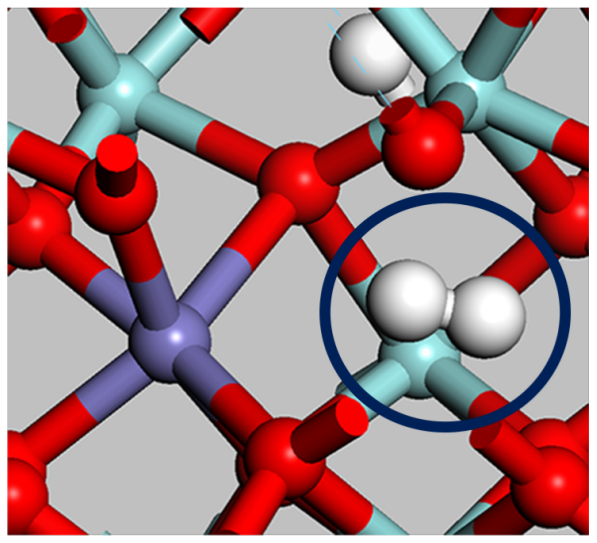

(e)

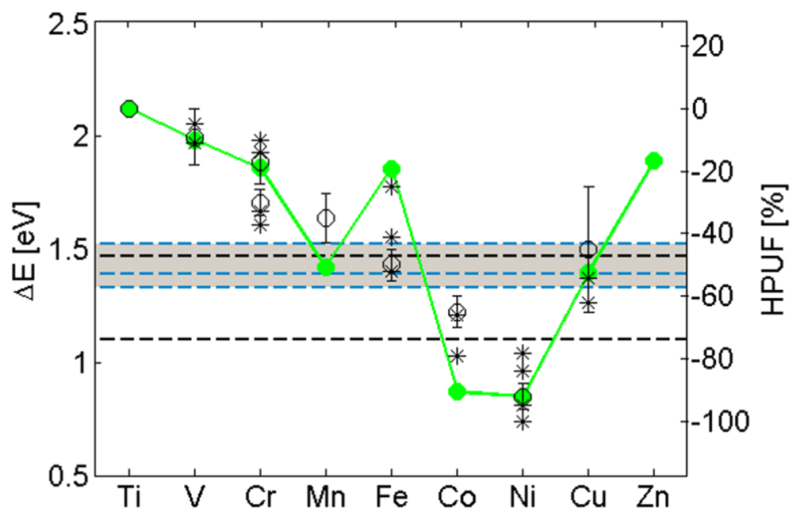

Figure 1: (a) Representative structure for a model of a hydroxylated inter-grain interface comprising $\mathrm{ZrO}(\mathrm{OH})_{2}$ on $\mathrm{ZrO} 2$. Here, this interface is decorated with $\mathrm{Fe}$ ions with the oxidation state +2 . Oxygen is represented as red, zirconium as light blue, iron as purple, and hydrogen as white. (b) One hydride ion and one hydroxide moiety prior to the hydride-proton recombination to form $\mathrm{H}_{2}$ is displayed, reactant in Equation 6 . (c) The product in Equation 6 is displayed, including $\mathrm{M}^{\mathrm{X}}$ coordination to the additional oxygen ion replacing the hydride ion and the released grain boundary $\mathrm{H}_{2}$. (d) Hydride-proton recombination energies for $\mathrm{H}_{2}$ release into said interface (dashed black line at $1.1 \mathrm{eV}$ ), enthalpy change for $\mathrm{H}_{2}$ release at ambient pressure (dashed black line at $0 \mathrm{eV}$ ), and corresponding Gibbs energy change (dashed black line at $-0.2 \mathrm{eV}^{2}$. $\mathrm{TM}^{2+}$ blue, $\mathrm{TM}^{3+}$ red, weighted average green. (e) Comparison of theoretical data (green) and experimental HPUF data (black); ${ }^{*}$ from [7] and ${ }^{\circ}$ from [8]. The theoretical data is a weighted average between $\mathrm{TM}^{2+}$ and $\mathrm{TM}^{3+}$. The black dashed line is HPUF in pure $\mathrm{ZrO}_{2}$ from [7]. The blue dashed line corresponds to $\mathrm{HE}$ from $\mathrm{Zr}^{4+}$ hydride at $\mathrm{GB}$ with $\mathrm{Na}^{+}, \mathrm{Ca}^{2+}$ and $\mathrm{Sc}^{3+}$ spectator. $\mathrm{Sc}^{3+}$ corresponds to the top line, $\mathrm{Na}^{+}$to the middle line and $\mathrm{Ca}^{2+}$ to the bottom line. 
(Figure 2). The line at $0 \mathrm{eV}$ represents the energy of a free $\mathrm{H}_{2}$ molecule at $0 \mathrm{~K}$. The line at $1.1 \mathrm{eV}$ represents the energy cost at $0 \mathrm{~K}$ for bringing a free $\mathrm{H}_{2}$ molecule into the confinement represented by Figure 1c. The line at $-0.2 \mathrm{eV}$ is owing to the increase in entropy when a water molecules $\mathrm{H}_{2} \mathrm{O}(\mathrm{l})$ is consumed $\left(-70.0 \mathrm{Jmol}^{-1} \mathrm{~K}^{-1}[10]\right)$ and a $\mathrm{H}_{2}(\mathrm{~g})$ molecule is formed $\left(130.7 \mathrm{Jmol}^{-1} \mathrm{~K}^{-1}[10]\right)$ at $298 \mathrm{~K}$ and $100 \mathrm{kPa}$ (compare Equation 1), while neglecting changes in entropy in $\mathrm{Zr}$ upon oxidation.

Thus, a perfect electro-catalyst would exhibit an enthalpy change of $0 \mathrm{eV}$ for the HER under ambient conditions. Moreover, it is inferred that a perfect electro-catalyst, which passes the HER into this hydroxylated interface via Equation 6 prior to the subsequent $\mathrm{H}_{2}$ release under ambient conditions, must display $1.3 \mathrm{eV} / \mathrm{H}_{2}$ overpotential, i.e., $(1.1-(-0.2)) \mathrm{eV} / \mathrm{H}_{2}$. Equivalently, in case of the HER into the interface, any residual drive towards $\mathrm{H}_{2}$ formation relative to the line at $1.1 \mathrm{eV} / \mathrm{H}_{2}$ corresponds to a local overpotential for the HER into the confining interface. A correlation emerges between a greater overpotential and a lower hydrogen pick-up fraction (HPUF, see Figure $1 \mathrm{~d}$ and 1e). Thus the well-known effect of $\mathrm{Ni}^{2+}$ to cause detrimental hydrogen pick-up was explained by its reluctance to release $\mathrm{H}_{2}$ into the hydroxylated internal inter-grain interface [4,5]. From the overall agreement between reaction energies for Equation 6 and the experimentally reported HPUF's, it was concluded that "anti-catalysts" are preferred in order to mitigate the HPUF. In case of zirconium oxidation by water, these "anti-catalysts" are ions, which conserve significant fractions of the drive for hydrogen evolution by forming highly reactive metastable hydrides. These species are contrasted by $\mathrm{Co}^{2+}$ and $\mathrm{Ni}^{2+}$, which catalyze the HER when $\mathrm{H}_{2}$ is released into the highly constraining interface (see Figures 1d and $1 \mathrm{e})$.

A stability check on the semi-quantitative validity of the model was offered by a comparison of the experimental $44 \%$ hydrogen pick-up fraction of pure zirconium (corresponding to the black horizontal dashed line at $1.5 \mathrm{eV} / \mathrm{H}_{2}$ ) and model calculations for the hydride-proton recombination energetics employing the inert $\mathrm{Na}^{+}, \mathrm{Ca}^{2+}$, and $\mathrm{Sc}^{3+}$ as "dummy" ions in the positions of the transition metal ions (see the three blue horizontal dashed lines in Figure 1e).

\section{On HER at ambient conditions - a consis- tency check}

According to the above understanding, which ions constitute viable electro-catalysts in the absence of confinement or at atmospheric pressure? In as much as the drive for HER comprises the relaxation of the resulting oxy-hydroxy ions coordinating the transition metal ion [4], it is suggested that besides being able to form the hydride intermediate, metals with low oxidation states and large ionic radii should be considered in order to minimize their affinities to the oxide surrounding. This characterization clearly points to the noble metal ions as candidates for electro-catalysts. Additional requirements for any successful electro-catalyst include sufficient electron conductivity of the oxide matrix supporting the catalyst as well as electric contact to the electrode itself. Finally, the "water dissociation catalysis" put forward by Subbaraman et al. [2,3] is used to infer that hydroxylated interfaces provide natural channels for proton transport to the oxy-hydroxide supported electro-

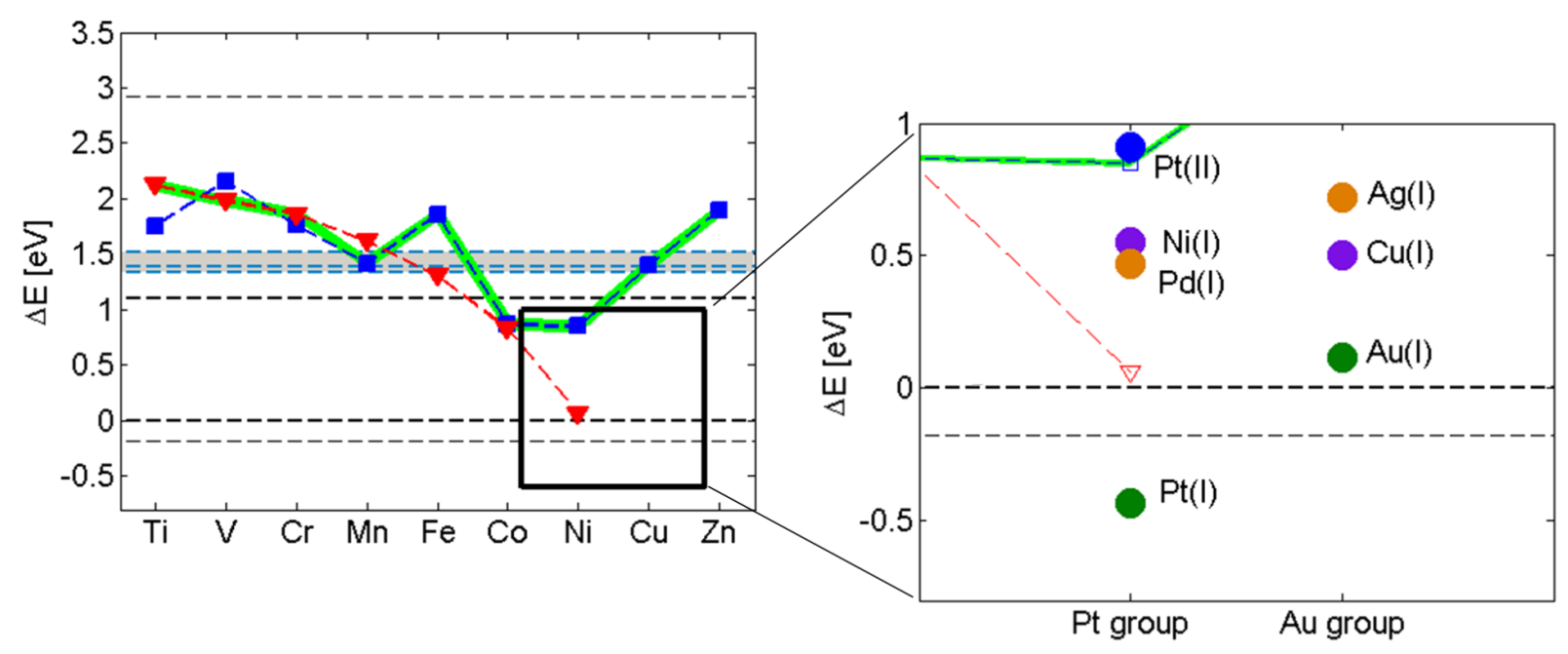

Figure 2: The diagram on the left is identical to Figure 1d. The enlarged region exposes the overpotentials for the elements in the Pt and Au groups. Note that $\mathrm{Pt}^{+}$associated hydride displays a negative overpotential implying that it is more stable than the $\mathrm{H}_{2}(\mathrm{~g})$ asymptote (lower dashed line). 
catalytic site. A schematic representation of this understanding of the electrode/electro-catalyst assembly is provided in Figure 3.

Employing the above described hydroxylated inter-grain interface model as a generic supporting matrix for the eletrocatalytic process, we evaluate the energetics for the hydride-proton recombination reaction and arrive at a possible descriptor for the HER, which is also applicable under ambient conditions. This facilitates a procedure for the screening among candidate electro-catalysts.

Indeed, in Figure 2, a descending staircase-like curve for electro-catalysts is arrived at for the reaction energy corresponding to Equation 6. Starting at the hydroxylated zirconia inter-grain confinement, where $\mathrm{Co}^{2+}$ and $\mathrm{Ni}^{2+}$ are the obvious candidate catalysts, we approach the ambient conditions step by step by considering the embedded $\mathrm{Ag}^{+}, \mathrm{Ni}^{+}, \mathrm{Cu}^{+}, \mathrm{Pd}^{+}, \mathrm{Au}^{+}$and eventually $\mathrm{Pt}^{+}$. The Sabatier principle applies in two ways. Firstly, $\mathrm{X}$ in $\mathrm{M}^{\mathrm{X}}$ can be made to satisfy the requirement that the reactant in Equation 6 forms spontaneously [4,5]. Secondly, the environment confining $\mathrm{H}_{2}$ in Equation 6 can be tuned to equalize the stabilities of reactants and products, so that any drive to release $\mathrm{H}_{2}$ into a confinement is balanced owing to the replacement of the three-centered hydride by an oxy-bridge (Equation 6). It is gratifying to find that the oxy-hydroxide supported $\mathrm{Au}^{+}$and $\mathrm{Pt}^{+}$sites become preferred only when approaching ambient conditions, as oxides of noble metals are generally unstable, a property which is often associated with their softness. Consequently, the drive to replace the hydride ion by an oxygen ion is weak, and hence the $\mathrm{H}_{2}$ release is expected to require a loose confinement for these systems. This is in contrast to harder ions, which form more stable oxides. Interestingly, in case of $\mathrm{Pt}^{+}$, the hydride comes out more stable than the $\mathrm{H}_{2}$ (g) limit. This implies that the embedded $\mathrm{Pt}^{+}$site could constitute an efficient absorber of $\mathrm{H}_{2}$ in the gas phase under ambient conditions - a purely chemical property. The semi-quantitative nature of the methodology does not allow for precise predictions of absolute numbers (see horizontal "error bar" in Figure 1e). However, it may be that the overpotentials reported for the Pt-based catalysts are related to the coverage dependence of the electrochemical decomposition of the $\mathrm{Pt}^{+}$
(A)

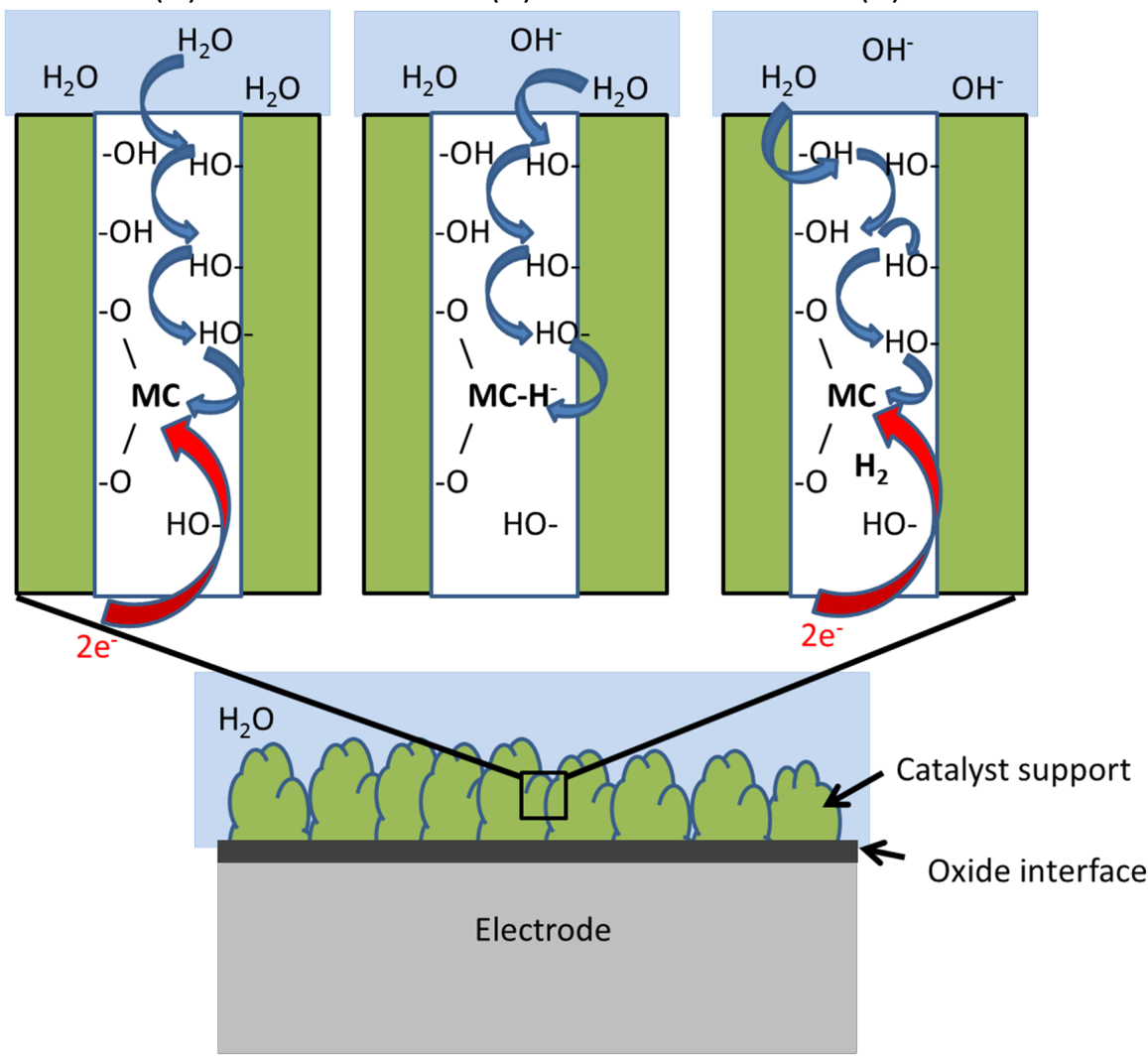

Figure 3: HER at electro-catalyst/electrode assembly. (A) Coalescence of proton and electrons to form the metal catalyst (MC) associated hydride, (B) Hydride-proton recombination to form $\mathrm{H}_{2}$ at the interface. (C) The step between panel $\mathrm{B}$ and panel $\mathrm{C}$ comprises the HER following the hydrideproton recombination step. 
associated hydride compound. Detailed properties of the embedding materials (e.g., electron conductivity) could cause the additional variations of the overpotential observed by Subbaraman et al. [2].

Interestingly, +2 is not considered a relevant oxidation state in case of Pt under ambient conditions for the electro-catalytic reaction path involving the hydride-proton recombination reaction (see Figure 2). This result is due to the strong binding of +2 to the oxy-hydroxide ligands upon $\mathrm{H}_{2}$ release, violating Sabatiers principle.

In conclusion, the present approach offers a complementary computational strategy to rank catalysts for HER from water splitting. The complex modelling of heterogeneous HER electro-catalysis at the interface between composite catalyst/ support and a water based electrolyte is subdivided into a chemical oxide hydrolysis step (Equation 2), an electro-chemical redox step (Equation 3, Equation 4 and Equation 5), followed by the chemical hydride-proton recombination step (Equation 6). This conceptual deconstruction aims for supporting the prediction of novel approaches to improve on existing electro-catalyst/electrode assemblies. Thus, the design of the aqueous electrolyte/substrate system impacts only the hydrolysis step (Equation 2). The oxidation state $\mathrm{X}$ of $\mathrm{M}^{\mathrm{X}}$ is decided by Equation 5, while the choice of supported HER catalyst $\mathrm{M}^{\mathrm{X}}$ is determined according to Equation 6 by the confinement effect in conjunction with Sabatier's principle.

For the HER step, a recently proposed alternative to the Volmer-Heyrovsky mechanism was employed [4,5]. Rather than electron-proton discharge over an $\mathrm{M}-\mathrm{H}$ moiety resulting in the conversion of $2 \mathrm{H}$ into $\mathrm{H}_{2}$, the HER investigated here results from a hydride-proton recombination reaction. While the protons constitute hydroxides in Equation 6, which is nonsignificant due to their ubiquity in aqueous media, an observation of three-center hydride intermediates is the sought-after "smoking-gun" evidence for the proposed mechanism.

\section{Computational details}

The Perdew-Burke-Ernzerhof generalized gradient approximation PBE GGA [11] as implemented in the DMOL3 engine $[12,13]$ in the Material Studios program package [14] was employed in conjunction with a double- $\zeta$ numerical basis set with an extra polarization function on each heavy atom and a p-function on each hydrogen atom. Systematic spin polarized calculations were performed. A $4 \times 4 \times 1 \mathrm{k}$-point set for sampling the Brillouin zone was compared to a $2 \times 2 \times 1$ k-point set, and the latter was found to suffice. In order to reduce the computational effort, inert electron shells were described effectively by means of the semi-core pseudopoten- tials. Zero-point corrected free energies were compared to noncorrected reaction energies and the differences were deemed negligible.

The grain boundary model (cf. Figure 1a) was constructed by inserting one unit cell of monoclinic $\mathrm{ZrO}(\mathrm{OH})_{2}(5.4 \AA \times 10 \AA \times$ $5.4 \AA)$ in between two supercells of monoclinic $\mathrm{ZrO}_{2}(5.4 \AA \times$ $10.8 \AA \times 5.4 \AA$ ), where the unit cell doubling is in the b-direction. The stability of the model has been extensively investigated, including full geometry optimization, when arriving at the foundation of [4]. The choice of the grain boundary model is far from unique. Here, it is the success in reproducing the experimental volcano shape curve (cf. Figure 1d) which renders the present investigation meaningful.

The grain boundary model employed to evaluate the reaction energy of Equation 6 was subjected to periodic boundary conditions, where the studied super-cell contained approximately 50 atoms. The number of hydrogen atoms, i.e., hydroxides and hydride, varied. This was because the oxidation states of the transition metal ions were controlled by adding (removing) hydrogen atoms to (from) the super-cell. This way, neutral super-cells were employed in all cases. When evaluating Equation 6 , all bond distances and bond angles associated with atoms in the super-cell were optimized, while the super-cell dimensions were kept constant.

\section{Acknowledgements}

The Swedish Research Council, Westinghouse Electric Sweden, Sandvik Materials Technology, Vattenfall and the EPRI are gratefully acknowledged for financial support.

\section{References}

1. Chlistunoff, J. Final Technical Report - Advanced Chlor-Alkali Technology; Los Alamos National Laboratory: Los Alamos, NM, 2004.

2. Subbaraman, R.; Tripkovic, D.; Chang, K.-C.; Strmcnik, D.; Paulikas, A. P.; Hirunsit, P.; Chan, M.; Greeley, J.; Stamenkovic, V.; Markovic, N. M. Nat. Mater. 2012, 11, 550-557. doi:10.1038/nmat3313

3. Subbaraman, R.; Tripkovic, D.; Strmenik, D.; Chang, K.-C.; Uchimura, M.; Paulikas, A. P.; Stamenkovic, V.; Markovic, N. M. Science 2011, 334, 1256-1260. doi:10.1126/science.1211934

4. Lindgren, M.; Panas, I. RSC Adv. 2013, 3, 21613-21619. doi:10.1039/c3ra42941e

5. Lindgren, M.; Sundell, G.; Panas, I.; Hallstadius, L.; Thuvander, M.; Andrén, H. O. Zirconium in the Nuclear Industry: Seventeenth International Symposium, Hyderabad, Feb 3-7, 2013; Comstock, R. J., Ed.; ASTM: West Conshohocken, PA; tentatively accepted.

6. Stewart, M. P.; Ho, M.-H.; Wiese, S.; Lindstrom, M. L.; Thogerson, C. E.; Raugei, S.; Bullock, R. M.; Helm, M. L. J. Am. Chem. Soc. 2013, 135, 6033-6046. doi:10.1021/ja400181a

7. Parfenov, B. G.; Gerasimov, V. V.; Venediktova, G. I. Corrosion of Zirconium and Zirconium Alloys (Korroziya tsirkoniya i ego splavov); Atomizdat: Moskva, 1976; pp 118-120. 
8. Cox, B. In Advances in Corrosion Science and Technology; Fontana, M. G.; Staehle, R. W., Eds.; Plenum: New York, 1976; Vol. 5, pp 173-391. doi:10.1007/978-1-4615-9062-0_3

9. Electrochemical Series. In CRC Handbook of Chemistry and Physics Online, 94th ed.; Haynes, W. M., Ed.; 2013.

10. Standard Thermodynamic Properties of Chemical Substances. In CRC Handbook of Chemistry and Physics Online, 94th ed.; Haynes, W. M., Ed.; 2013.

11. Perdew, J. P.; Burke, K.; Ernzerhof, M. Phys. Rev. Lett. 1996, 77, 3865-3868. doi:10.1103/PhysRevLett.77.3865

12. Delley, B. J. Chem. Phys. 1990, 92, 508-517. doi:10.1063/1.458452

13. Delley, B. J. Chem. Phys. 2000, 113, 7756-7764. doi:10.1063/1.1316015

14. Materials Studio 6.0; Accelrys Software Inc., 2011.

\section{License and Terms}

This is an Open Access article under the terms of the Creative Commons Attribution License

(http://creativecommons.org/licenses/by/2.0), which permits unrestricted use, distribution, and reproduction in any medium, provided the original work is properly cited.

The license is subject to the Beilstein Journal of

Nanotechnology terms and conditions:

(http://www.beilstein-journals.org/bjnano)

The definitive version of this article is the electronic one which can be found at: doi:10.3762/bjnano.5.21 